\title{
The Editorial Leadership of Academic Psychiatry
}

\author{
Honor Hsin ${ }^{1}$
}

Received: 9 November 2015 / Accepted: 10 November 2015 / Published online: 13 January 2016

(C) Academic Psychiatry 2016

Academic Psychiatry seeks to advance knowledge and the practice of education, leadership, administration, and ethics in psychiatry, as well as scholarship on professional development and wellness. With recent growth at the journal, including an increasing number of manuscript submissions and a move to an international publishing platform through Springer Science+Business Media, LLC, the editorial leadership of the journal has expanded significantly to enhance the journal's service to authors and readers. The editorial leaders aim to promote a broad range of interests expressed by the journal's audience, while upholding the highest standards of academic publication. Editors also contribute to an enhanced representation of the four sponsoring organizations of the journal: The American Association of Chairs of Departments of Psychiatry, the American Association of Directors of Psychiatric Residency Training, the Association for Academic Psychiatry, and the Association of Directors of Medical Student Education in Psychiatry. We introduce here the members of the Academic Psychiatry editorial team, who graciously give their time, knowledge, and skills to the continuing enrichment of the journal.

Honor Hsin

honor@stanford.edu

1 Stanford University School of Medicine, Stanford, CA, USA

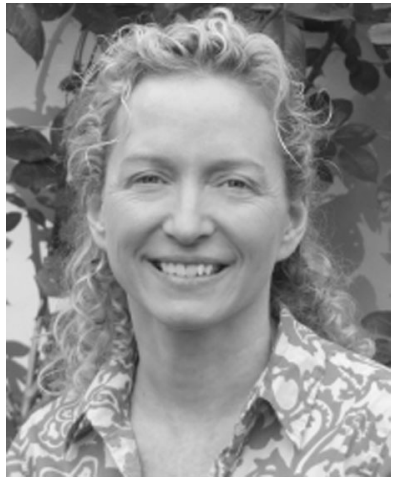

\section{Laura Weiss Roberts} Editor-in-Chief

Laura Weiss Roberts, M.D., M.A., first began working with Academic Psychiatry in 1996, when the editor-in-chief, Jonathan Borus, M.D., gave her the opportunity to develop (with Teresita McCarty, M.D.) the first special theme issue published by the journal ("Education of Psychiatry Residents in Ethics," Volume 20, Issue 3). Dr. Roberts served as the Assistant to the Editors before being selected as the Editor-in-Chief in 2002 through a national, competitive search process. Since her appointment, two new professional societies (the Association of Directors of Medical Student Education in Psychiatry and the American Association of Chairs of Departments of Psychiatry) joined the original professional societies (the Association for Academic Psychiatry and the American Association of Directors of Psychiatric Residency Training) to sponsor the journal. Dr. Roberts has 
evaluated more than 2000 new manuscripts for publication in the journal and mentored many early-career authors to help support their academic success. Dr. Roberts led the journal through the process of transitioning to its new publisher, Springer, bringing greater prominence and a worldwide platform for the journal.

Dr. Roberts serves as Chairman and Katharine Dexter McCormick and Stanley McCormick Memorial Professor in the Department of Psychiatry and Behavioral Sciences at the Stanford University School of Medicine. Dr. Roberts has received extensive scientific, peer-reviewed funding from the National Institutes of Health (NIH), the Department of Energy, and private foundations to perform empirical studies of modern ethical issues in research, clinical care, and health policy, with a particular focus on vulnerable and special populations. Dr. Roberts has written hundreds of peer-reviewed articles and other scholarly works, and she has written and edited several books on professionalism and ethics in medicine, professional development for physicians, and clinical psychiatry. An NIH career scientist, she is a nationally recognized scholar and leader in ethics, psychiatry, medicine, and medical education and has undertaken many roles across academic medicine.

Dr. Roberts has developed an outstanding editorial leadership team, as described below, who serve the journal with dedication, expertise, and generosity.

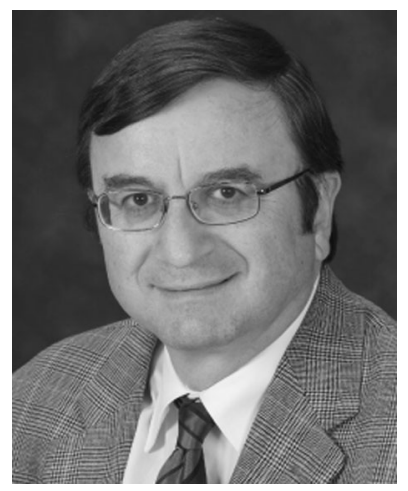

Richard Balon Deputy Editor

Richard Balon, M.D., D.L.F.A.P.A., FACPsych, is Professor of Psychiatry and Anesthesiology, Associate Chair for Education, and Program Director of the Adult Psychiatry Residency Training Program at the Department of Psychiatry and Behavioral Neurosciences, at Wayne State University School of Medicine. He has published widely in the areas of psychiatric education, sexual dysfunction associated with medications and human sexuality, the biology of anxiety, and clinical psychopharmacology, including several books. He started publishing in Academic Psychiatry with two Letters to the Editor, "Recruitment for Psychiatric Residency" in 1993 and "The Moral Myopia of Academia and "The Big Chill' of Managed Care" in 1994. His first research paper in the journal, "Characteristics of Directors of Medical Student Education in Psychiatry," appeared in 1998. He has been recognized with teaching awards from residents at Wayne State University, the First American Psychiatric Association (APA) Annual Nancy CA Roeske Certificate for Excellence in Medical Student Education, the 1999 Association for Academic Psychiatry Region VI Teacher of the Year Award, the 1998 APA George Tarjan Award, the 2005 APA Special Presidential Commendation, the 2011 APA/National Institute of Mental Health Vestermark Psychiatry Educator Award, and the 2013 Faculty Award for Excellence in Clinical Science Teaching at Wayne State University. He serves on the editorial boards of several journals and has served on the PRITE Editorial Board and the USMLE Part 2 Psychiatry Committee.

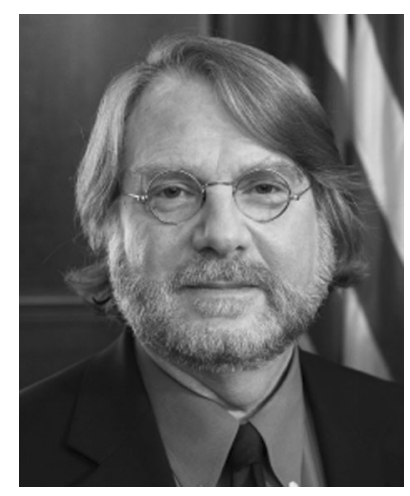

Eugene Beresin

Deputy Editor

Eugene V. Beresin, M.D., M.A., became a member of the Academic Psychiatry Editorial Board in 1996. He has been editor of the journal's Media Column since 1997 and was appointed Deputy Editor of the journal in 2013. Dr. Beresin has been a clinical educator his entire career. He was a program director from 1982 to 2014, serving as a training director in both general and child and adolescent psychiatry at Massachusetts General Hospital (MGH). He was Director of the MGH/McLean Child and Adolescent Psychiatry Residencies from 1990 to 2014 and President of the American Association of Directors of Psychiatric 
Residency Training (AADPRT) in 1997. Dr. Beresin has been awarded a number of local and national teaching awards including the Accreditation Council for Graduate Medical Education (ACGME) Parker Palmer Courage to Teach Award in 2002 and the American Psychiatric Association/National Institute of Mental Health Vestermark Award in 2004. He is Professor of Psychiatry at Harvard Medical School and director of a 2-year curriculum for all medical students, "The Developing Physician: Lifelong Integration of Personal and Professional Growth with Sensitive Compassionate Care." He is the Executive Director of the MGH Clay Center for Young Healthy Minds, which has as its mission public education on youth and family development and promotion of greater understanding and destigmatization of psychiatric disorders. Besides authoring academic papers, Dr. Beresin has consulted for numerous television and radio shows and blogs for the MGH Clay Center, the Huffington Post, and Psychology Today.

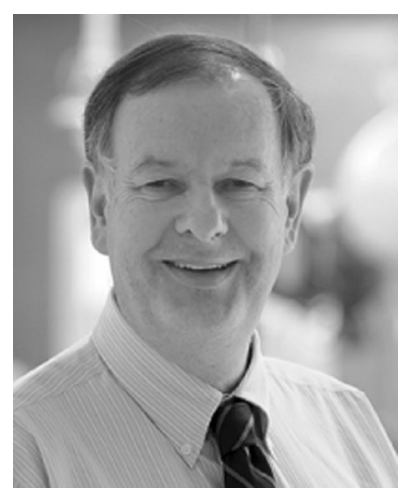

John Coverdale

Deputy Editor

John Coverdale, MB ChB., M.D., M.Ed., FRANZCP, became Associate Editor of Academic Psychiatry in 2003 and Deputy Editor of the journal in 2008. He is Professor of Psychiatry and Medical Ethics at Baylor College of Medicine and Adjunct Professor at the Weiss School of Natural Sciences, Rice University, and serves as a full-time clinician at Ben Taub Hospital, a public hospital. He has formally mentored many medical students, and he teaches courses including evidencebased medicine for medical students and ethics. He has published approximately 200 papers in peer-reviewed journals. One major area of academic interest for Dr. Coverdale is medical education, for which he has published numerous articles, including in Academic Psychiatry. Other areas of his academic activity include topics at the interface of obstetricsgynecology and psychiatry, integrated care for patients with major mental disorders, ethics and professionalism, forensic psychiatry, and media depictions of mental illness. Dr. Coverdale has won many awards, including induction into Baylor's Outstanding Faculty Hall of Fame.

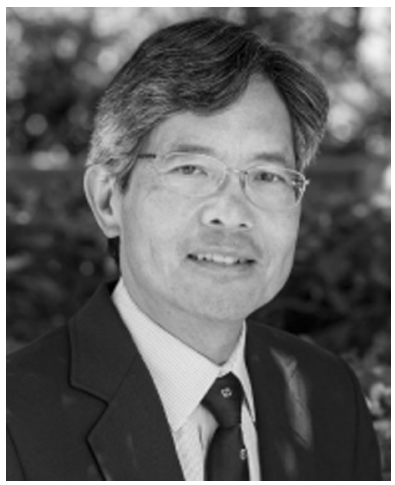

Alan Louie Deputy Editor

Alan K. Louie, M.D., joined the journal's editorial staff in 2003 as the result of a nationwide search for Associate Editors. Subsequently, he became a Deputy Editor, has been involved in editorial decisions on numerous manuscripts, and has written 44 articles for the journal. He is currently Professor, Associate Chair, and Director of Education in the Department of Psychiatry and Behavioral Sciences at the Stanford University School of Medicine. He was previously Clinical Professor of Psychiatry at the University of California, San Francisco (UCSF), where he was Director of the Anxiety and Affective Disorders Consultation Program, Acting Associate Director of Medical Student Education (Psychiatry), and Co-Director of the Brain, Mind, and Behavior course in the UCSF essential core curriculum. He was also Director of Psychiatry Residency Training for the San Mateo County Behavioral Health and Recovery Services in the San Francisco Bay Area and Director of Continuing Medical Education. He received from the National Institute of Mental Health a Physician Scientists Award (for career development), from the Accreditation Council for Graduate Medical Education (ACGME) the Parker J. Palmer Courage to Teach Award, and from the American Psychiatric Association the Irma Bland Award for Excellence in Teaching Residents and the Nancy C.A. Roeske Recognition of Excellence in Teaching Medical Students. His research interests have included neuropsychopharmacology, neuroscience, behavioral pharmacology, anxiety and affective disorders, and medical education. 


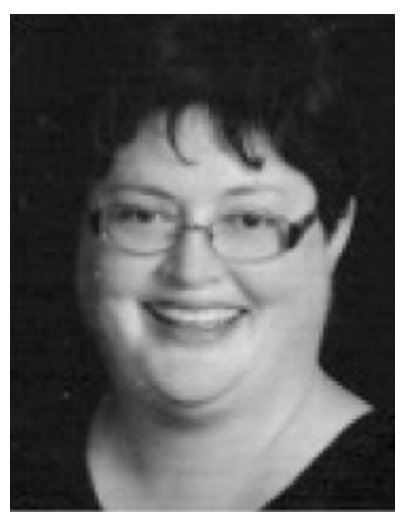

Ann Tennier

Senior Managing Editor

Ann Tennier, E.L.S., began assisting Dr. Roberts with her writing and editing projects at the Medical College of Wisconsin in 2006 and became part of the Academic Psychiatry editorial team as a result of Dr. Roberts' role as Editor-in-Chief for the journal. She earned certification from the Board of Editors in the Life Sciences in 2009 and transitioned to Stanford University School of Medicine with Dr. Roberts in 2010. As the journal's Senior Managing Editor, she works closely with Dr. Roberts and the editorial staff members to keep the journal running smoothly. She collaborates with the editors to review each new and revised manuscript submission and to plan the print issue lineups and special topic collections. She coordinates the journal's governance and editorial board meetings and reports, and she liaises with the publisher regarding journal production, subscriptions, and marketing and with the sponsoring organizations for their annual meetings and member communications.

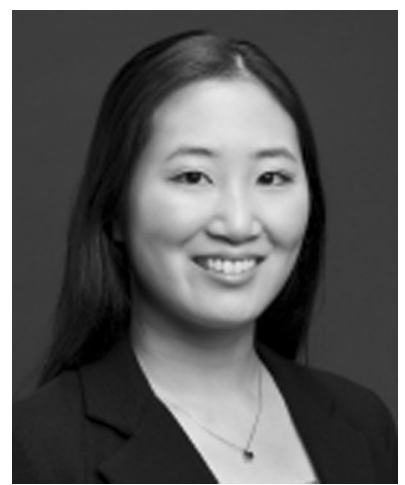

Honor Hsin

Assistant to the Editor

Honor Hsin, M.D., Ph.D., joined Academic Psychiatry as Assistant to the Editor in Summer 2015 to work directly with Dr. Roberts to enhance the initial review process for new manuscript submissions. She is a fourth-year resident in psychiatry at Stanford University School of Medicine. She received a Ph.D. in neurobiology from the Massachusetts Institute of Technology and an M.D. with specialization in health sciences and technology from Harvard Medical School. She has published original research, commentaries, and book chapters in various fields, including molecular genetics, neuroscience, psychopharmacology, ethics, and international relations. Her interests include the integration of scientific and technological innovations with psychiatric practice, educational publication for clinical training, and professional development. She has received the National Institute of Mental Health Outstanding Resident award, among other academic awards.

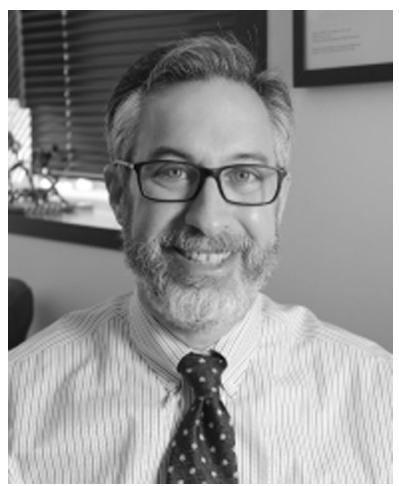

Adam Brenner

Associate Editor

Adam Brenner, M.D., is Professor of Psychiatry, Distinguished Teaching Professor, and Vice Chair for Education in Psychiatry. He graduated from Emory University, Magna Cum Laude in Philosophy. He attended Harvard Medical School and completed his psychiatry residency at McLean Hospital. Dr. Brenner's clinical focus is in treatment of anxiety and depressive disorders with a combination of psychoanalytic psychotherapy and psychopharmacology. His scholarly publications are on innovations in psychiatric education. Dr. Brenner is Co-Chair of the Psychotherapy Committee of the American Association of Directors of Psychiatric Residency Training (AADPRT) and serves on the Executive Council of AADPRT. Among his educational and teaching awards, he was recently elected to the University of Texas Academy of Health Science Educators and also received the University of Texas Regents' Outstanding Teacher Award. A graduate of the Boston Psychoanalytic Institute, Dr. Brenner is on the faculty of the Dallas Psychoanalytic Center. Dr. Brenner also serves on the board of the Dallas Chapter of Mental Health America and the Executive Committee of the North Texas Society of Psychiatric Physicians. Dr. Brenner is Co-Chair of the Dallas County Behavioral Health Leadership Team, a board chartered by the county to further coordination and collaboration among the various public psychiatry providers and stakeholders 
in the community. He has served on the Editorial Board of Academic Psychiatry since 2009.

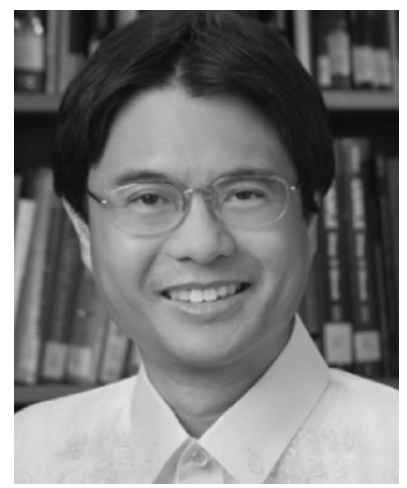

Anthony Guerrero

Associate Editor

Anthony P. S. Guerrero, M.D., is Professor and Chair of Psychiatry and Clinical Professor of Pediatrics at the University of Hawai'i John A. Burns School of Medicine, where he completed medical school and residency training in general pediatrics, general psychiatry, and child and adolescent psychiatry. Within his department, and at various times, he has served as a Director of Medical Student Education, Director of the Child and Adolescent Psychiatry Program and Division, and Associate Chair for Education and Training. He has published and presented on structured tools for problem-based learning, creative approaches to psychiatric education, Filipino and Asian/Pacific Islander mental health and workforce development, and the interface between primary care and psychiatry. He is the Co-Founding Editor of the Springer textbook Problem-based Behavioral Science and Psychiatry, which has a second edition in preparation. He has served on the Editorial Board of Academic Psychiatry since 2008 and is Assistant Editor of World Child and Adolescent Psychiatry, the official newsletter and e-journal of the World Psychiatric Association, Child and Adolescent Psychiatry Section.

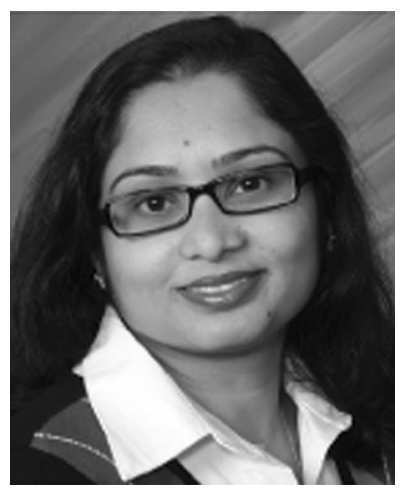

Rashi Aggarwal Assistant Editor
Rashi Aggarwal, M.D., is joining Academic Psychiatry as an Assistant Editor. She first published in the journal in 2014 as the first author of the paper "Teaching Empathy During Clerkship and Residency." She has served as a reviewer for the journal for 3 years. Dr. Aggarwal is an Associate Professor of Psychiatry and the Associate Director of Residency Training at Rutgers New Jersey Medical School in Newark, New Jersey. She serves as director for the Advanced Communication Skills course for second-year medical students. She has been active in her school's initiative to launch a revised curriculum. Her academic interests include stigma, empathy, undergraduate medical education and training, and acculturation issues for international medical graduates.

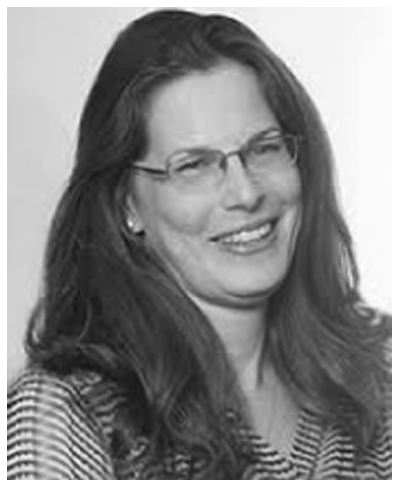

$$
\begin{aligned}
& \text { Michelle Goldsmith } \\
& \text { Assistant Editor }
\end{aligned}
$$

Michelle Goldsmith, M.D., M.A., joined Academic Psychiatry as Assistant to the Editor in 2011 and then as Assistant Editor in 2013. She is Clinical Assistant Professor of Child and Adolescent Psychiatry in the Department of Psychiatry and Behavioral Sciences at Stanford University School of Medicine. She also serves as the Assistant Training Director for the Child and Adolescent Psychiatry Fellowship at Stanford. She received her M.A. in Classical Philology from Rutgers University in 1999 and her M.D. from Drexel University in 2004. She completed her residency training in General Psychiatry at the University of Pennsylvania in 2008 and her fellowship in Child and Adolescent Psychiatry at Stanford in 2010. She has published commentaries, editorials, and book chapters in various fields, including ethics, medical student education, college mental health, professional development, and psychosomatic medicine. She is a consultant to the American Academy of Child and Adolescent Psychiatry Ethics Committee, and her interests include training and education of child and adolescent psychiatrists, psychosomatic medicine, teaching of ethics, and child and adult attention-deficit/hyperactivity disorder. She has received awards for clinical excellence in teaching and psychodynamic psychotherapy. 


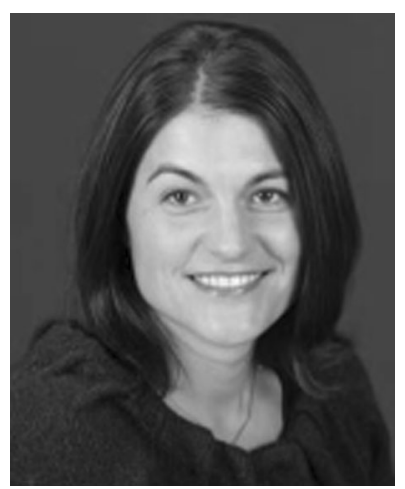

Mary Morreale

Assistant Editor

Mary Morreale, M.D., is joining the staff of Academic Psychiatry as an Assistant Editor. Dr. Morreale has reviewed manuscripts for the journal since 2009 and has authored six and co-authored four manuscripts. In addition, Dr. Morreale served as a Guest Editor for a special collection of articles on human sexuality education within psychiatry (Volume 34, Issue 5,2010) and writes book reviews with Deputy Editor Richard Balon for the journal's Literary Resources Column. Dr. Morreale is Associate Professor of Psychiatry and Behavioral Neurosciences and Director of Medical Student Education at Wayne State University in Detroit, Michigan. Her academic interests include medical student education and the interface between oncology and psychiatric illness. Dr. Morreale is actively engaged in teaching medical students and has won teaching awards and the Arnold P. Gold Foundation Leonard Tow Humanism in Medicine Award. She completed her residency training in psychiatry at the University of North Carolina.

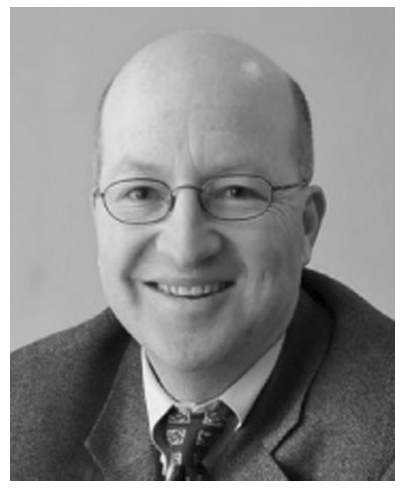

Steven Schlozman Assistant Editor

Steven C. Schlozman, M.D., became a member of the Editorial Board of Academic Psychiatry in 2009. He has authored or co-authored more than 40 publications, covering topics from psychiatric education to the effects and utility of popular culture in psychiatry, and he has investigated and written about the roots of stigma in psychiatric curricula. From 2005 to 2014, he served as Associate Director and then Co-Director of Medical Student Education in Psychiatry at Harvard Medical School (HMS), where he was also Course Director of the second-year course in psychopathology and Director of psychiatric electives. He is currently Course Director for the Massachusetts Institute of Technology (MIT)/HMS course in psychiatry and also teaches in the MIT/HMS neuroscience course. Dr. Schlozman served as Associate Program Director for the Child and Adolescent Psychiatry Residency Program at the Massachusetts General Hospital (MGH) and McLean Hospital and has received numerous teaching awards, both at Harvard and nationally. He was a member of the ED-2 Committee for the Association of Directors of Medical Student Education in Psychiatry that advised the Liaison Committee on Medical Education regarding the range of psychiatric illnesses that all medical students need to encounter as part of their medical education. Currently, Dr. Schlozman is Associate Director at the Clay Center for Healthy Young Minds at MGH and sees patients for the Transplant Service at MGH. He is also a published novelist, has written and published short stories, and teaches an undergraduate course at Harvard that focuses on the neurobiological, psychological, and social relevance of horror films. He blogs frequently for The Huffington Post and Psychology Today, and he has written articles for The New York Times Sunday Magazine, Psychology Today, The Southwest Airlines Magazine, Newsweek, and The Guardian.

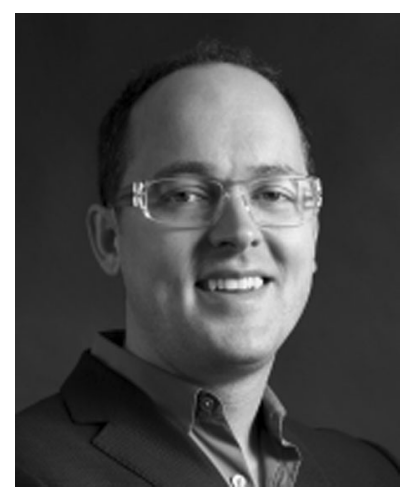

Glendon Tait

Assistant Editor

Glendon R. Tait, M.D., M.Sc., FRCPC, joined Academic Psychiatry as a peer reviewer in 2008, Editorial Board member in 2010, Co-Editor of Snap Shots articles in 2011, and Assistant Editor in 2013. He is Associate Professor of 
Psychiatry and Medical Education at Dalhousie University in Nova Scotia, Canada. Dr. Tait received his B.A. (Hons) from the University of New Brunswick, an M.Sc. in Psychopharmacology from the University of Alberta, and M.D. from the University of Calgary - an innovative medical school where his interest in medical education was born. He completed his residency in the University of Toronto Department of Psychiatry, where he also completed the department's Clinician Scientist Program with medical education as a scholarly focus. He completed a Fellowship in Medical Education at the Wilson Center for Research in Education and Postgraduate Certificate in Medical Education from the University of Dundee. As a resident, he received fellowship awards from the Association for Academic Psychiatry and the Academy of Psychosomatic Medicine. As a clinician educator and consultation-liaison psychiatrist, Dr. Tait has researched the use of narrative within physician education, attitudinal development, the hidden curriculum, and how health care teams deliver care in the context of complex medical illness. He is interested in how health system challenges and medical education interact with each other, employing lenses such as complexity science to understand such questions. Dr. Tait is also Chair of the Canadian Psychiatric Association Annual Conference Committee and Vice-President of the Canadian Academy of Psychosomatic Medicine and serves on the Continuing Professional Development committees of both organizations. He has also served on the Medical Council of Canada Standard Setting Panel and is currently on the Psychiatry Examination Committee and the Dalhousie University Steering Committee on Competency Based Medical Education.

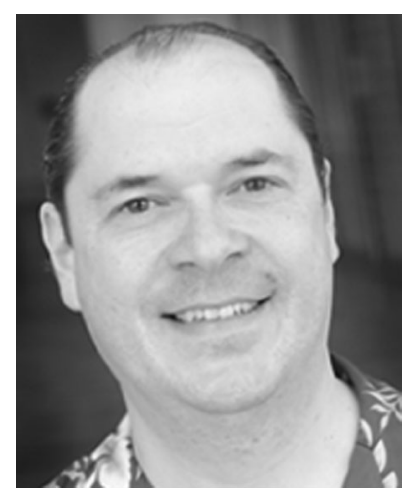

Donald Hilty

Technology Innovation Column Editor

Donald Hilty, M.D., is Professor and Vice-Chair of Education and Director of Telepsychiatry and Distance Education at the Keck School of Medicine at the University of Southern California. His current research involves telepsychiatric models of care and education to primary care, including a current Agency for Healthcare Research and Quality randomized control trial comparing synchronous and asynchronous telepsychiatry. Dr. Hilty's specific scholarship extends significantly into publishing (180+ articles/chapters/books), serving as editor of two journals (Journal of Technology in Behavioral Sciences and Psychology and Cognitive Science) and working on several Editorial Boards (Academic Psychiatry, Focus, Journal of Psychiatry, Depression and Anxiety). He has a new book in press with Springer Publishing titled Key Issues in e-Mental Health. $\mathrm{He}$ is helping to lead efforts in faculty development and mentoring for the Association for Academic Psychiatry, the Association of Directors of Medical Student Education in Psychiatry, and the American Association of Directors of Psychiatric Residency Training. In the past, he chaired scientific programs for the American Association of Medical Colleges Western Group of Medical Educators, the American Psychiatric Association, and the Association for Academic Psychiatry. He is a Member of the Writing Groups for the American Psychiatric Association-Institute of Medicine and American Telemedicine Association Clinical Practice Guidelines.

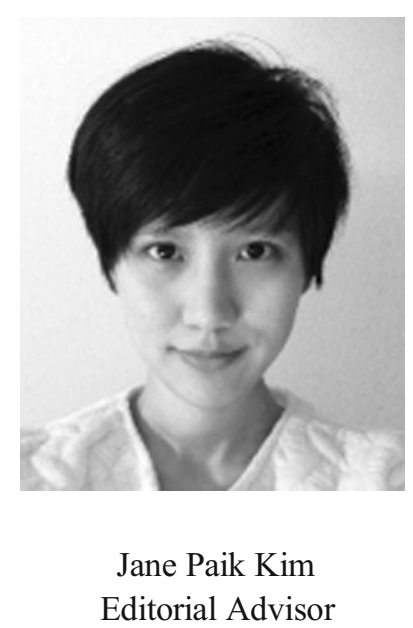

Jane Paik Kim, Ph.D., has served as a journal Editorial Advisor since 2014. She was first published in the journal as a co-author to the research paper "Experiences of Residents with Informal Health Care Practices: Curbside Consultation and Self-Diagnosis and Treatment" in 2015. She has actively served as a peer reviewer for the journal, with 17 papers reviewed since 2014. Dr. Kim is also Instructor of Biostatistics at the Department of Psychiatry and Behavioral Sciences at Stanford University School of Medicine. She has published in the areas of ethics in psychiatry, as well as other areas in medicine and statistics. 


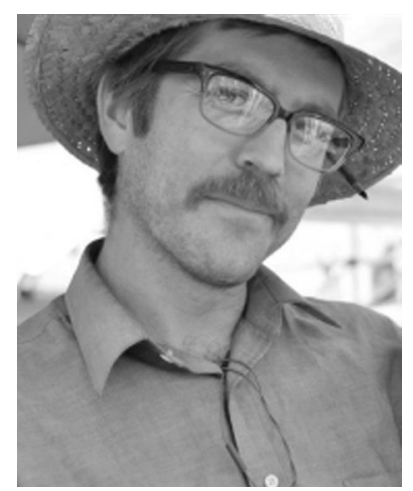

Kyle Lane-McKinley

Art and Creative Works Advisor

Kyle Lane-McKinley, M.F.A., is an artist and educator in Santa Cruz, California, where he lives with his partner and his daughter. Kyle completed an M.F.A. in the Digital Art and New Media program at the University of California, Santa Cruz in 2010, where he continues to work as a Lecturer, Research Associate, and Coordinator of the Social Practice Arts Research Center (SPARC). 